可視化情報 Vol.20 Suppl. No.1（2００００年７月）

江上 泰広 ${ }^{\circ}$, 浅井 圭介, 天尾 豊 (航空宇宙技術研究所), 藤 敦彦, 手塚 宣和, 亀田 正治 (東京農工大学)

\title{
Visualization of the vortex breakdown on a delta wing with Pressure-Sensitive Paint
}

\author{
Yasuhiro EGAMI, Keisuke ASAI, Yutaka AMAO, \\ Atsuhiko FUJI, Norikazu TEDUKA and Masaharu KAMEDA
}

\begin{abstract}
The leading-edge vortices on a delta wing are visualized by using a pressure-sensitive paint (PSP). This technique is based on the oxygen quenching of luminescent molecules. In this experiment, the paint composed of PtOEP and fluorine polymer was adopted because it showed high sensitivity to the pressure and low sensitivity to temperature. A thin paint coating was applied on a delta wing model composed of aluminum. The paint was excited by a Xenon light and the luminescent images were obtained using a highresolution CCD camera. The obtained images were analyzed on a personal computer. The complicated flow structures on the delta wing including vortex breakdown were visualized clearly by using the pressure-sensitive paint.
\end{abstract}

Keywords: Pressure-Sensitive Paint, Image Analysis, Delta wing, Leading edge vortices, Vortex breakdown

\section{1. 緒 言}

物体まわりの流れ場の情報を得るために従来様々な方 法の可視化が行われてきている。壁面の流れ場の可視化 には,オイルフロー法などが用いられている。しかしそれ らの方法では, 詳細な流れ場の定量的情報を得ることは 困難である。そこで本研究では, 感圧塗料を用いた流れ場 の可視化を試みた。

感圧塗料とは励起光を照射すると燐光を発する色素を 含む塗料で, 酸素消光によって発光強度が変化するもの である。既知の圧力 $P_{r e f}$ における発光強度を $I_{r e f}$ とする と, 圧力 $P$ と発光強度 $I$ の関係は Stern-Volmer の関係式 で(1)式のように記述することが出来る。

$$
\frac{I_{r e f}}{I}=A+B \cdot \frac{P}{P_{r e f}}
$$

ここで $A, B$ は定数である。基準となる無風時データ $I_{r e f}$ と通風時データ $I$ の発光強度の比 $I_{r e f} / I$ を求めることに より, モデル上の圧力分布の定量的情報を得ることがで きる。

この無風時と通風時の発光強度分布は $\mathrm{CCD}$ カメラで

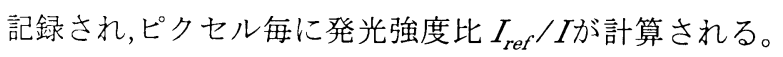
しかし,通風時には空気力により,モデルの移動や変形が
生じたり,測定部自身が熱で移動したりしてしまい, 2 画 像間のモデルのずれが生じ,測定精度を劣化させてしま う。そのためこれらの移動などによる画像のずれを適切 に修正することが必要になる。また,画像データにはショ ットノイズなどのノイズが含まれている。そのノイズを 取り除くためフィルタリングなどの処理が必要となる。

本研究では,航技研小型超音速風洞において試験した 感圧塗料を用いたデルタ翼モデルの可視化法と得られた 画像の処理法及びその結果について述べる。

\section{2. 実験装置及びその方法}

\section{1 感圧塗料}

使用した感圧塗料は色素に白金オクタエチルポルフィ リン(PtOEP),バインダーにフッ素系ポリマーを用いた 塗料である。従来,感圧塗料は圧力だけでなく温度変化に よっても発光強度が変化し,この温度感度が圧力測定の 誤差の大きな原因になってきた。しかしこのバインダ一 にフッ素系ポリマーを用いた感圧塗料は従来のシリコン ポリマー(GP197)を用いたものと比較して温度感度が非 常に小さく, 高精度の測定を可能とする ${ }^{1)}$ 。感圧塗料はデ ルタ翼模型にスプレーで薄く塗布した。

\section{2 実験装置}

可視化実験は航技研の小型超音速風洞を用いて行った。 
この超音速風洞は連続回流式風洞で测定部の断面は $200 \mathrm{~mm} \times 200 \mathrm{~mm}$ となっている。尖験に用いたデル夕翼 モデルをFig. 1 に示す。模型は全長 $\mathrm{C}=100 \mathrm{~mm}$, 後退角 $70^{\circ}$ のアルミ製である。前縁はシャープエッジとなって いる。模型は風洞澌定部内に気流に刘して迎角 $\alpha=20^{\circ}$ 从び $30^{\circ}$ で取り付けられた。

Fig. 2 に風洞試験で用いた光学系の概略を示す。風洞 側壁はUV 透過性のアクリル板で作られておりこここを 通じて测定及び倠察を行った。感厈塗料の蛍光物質の励 起には $400 \pm 50 \mathrm{~nm}$,カメラには $650 \pm 20 \mathrm{~nm}$ の十渉フィ ルターを取り付けた。発光強度の测定には浜松ホトニク 又製の高感度 CCD カメラ（解像度 $14 \mathrm{bit}$, 有效画素数 $1000 \times 1018$ ピクセル) を用いた。カメラによって得ら れた画像はコンピューターに取り込まれ記録された。叮 視化実験が行われたマッ八数,迎角, 総厈, 総温,レイノル ズ数 $(R e=U C / v)$ の条件はTable 1 のと抢りである。

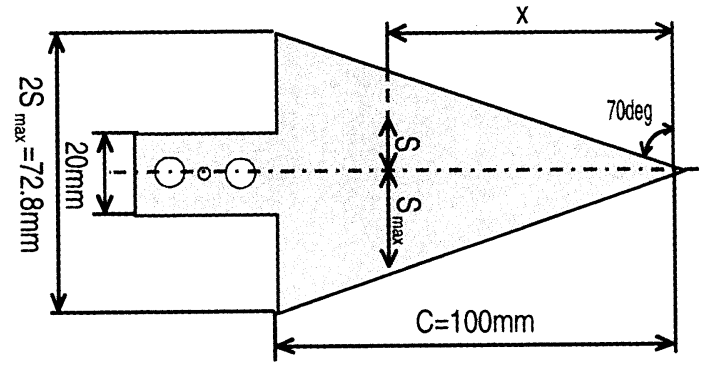

Fig. 1 Delta-wing model

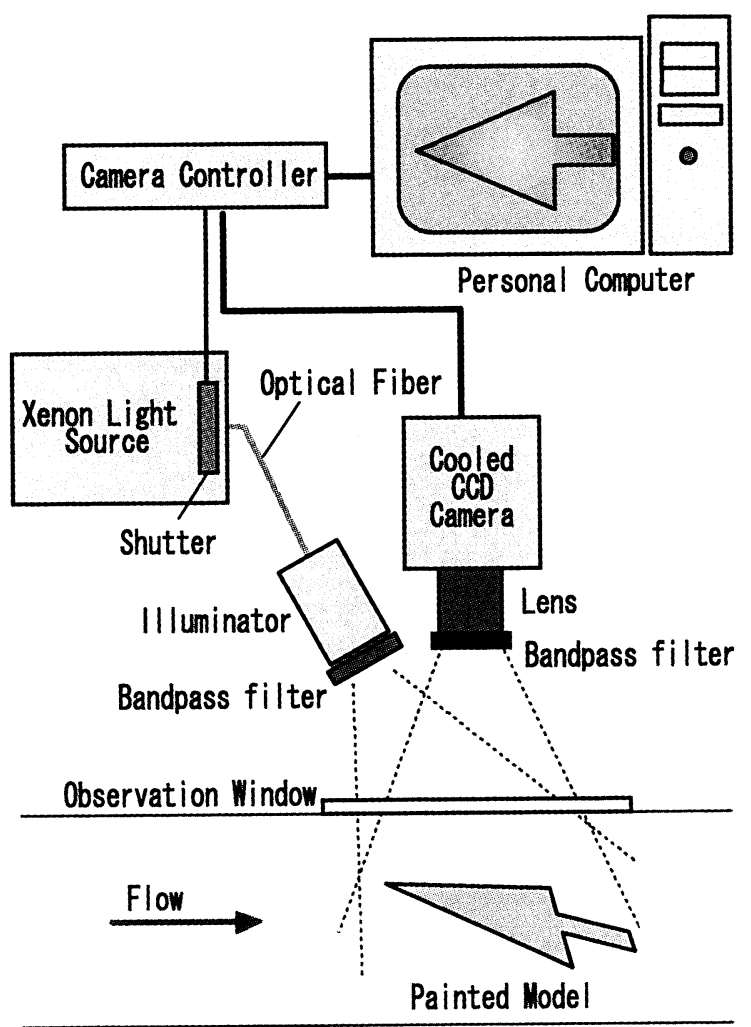

Hind Tunnel

Fig. 2 Experimental Set-ups
Table 1 Condition of visualizations

\begin{tabular}{|c|c|c|c|c|}
\hline マッハ数 & 迎角 $\alpha$ & 総厉 $P$ & 総温 $T$ & $R c$ \\
\hline$M=0.59$ & $20^{\circ}, 30^{\circ}$ & $60.1 \mathrm{kPa}$ & $320.0 \mathrm{~K}$ & $6.1 \times 10^{5}$ \\
\hline$M=0.78$ & $20^{\circ}, 30^{\circ}$ & $60.1 \mathrm{kPa}$ & $320.0 \mathrm{~K}$ & $7.2 \times 10^{5}$ \\
\hline$M=0.60$ & $30^{\circ}$ & $\begin{array}{c}60 \mathrm{kPa} \sim \\
100 \mathrm{kPa}\end{array}$ & $325.0 \mathrm{~K}$ & $\begin{array}{c}6.1 \times 10^{5} \sim \\
10.1 \times 10^{5}\end{array}$ \\
& & & & \\
\end{tabular}

\section{3. 画像処理法}

感厈塗料の発光強度画像の解析はパーソナルコンヒュ 一夕上で Matlabを用いて行った。そして, 叮能な限り良 質なデータを取り出すために以下の手順で画像処理を行 った。

1. 無風時,通風時それぞれの試験条件に刘し 12 枚掫影し た画像を平均化する。

2. カメラの喑電流ノイズを補止するため, ダーク画像を 通風时,無風時とも処理 1 の平均画像より引く。

3. 通風時,無風時の 2 画像間のモデルのずれを補止する

4。ローパスフィル夕を通風時,無風時双方の画像に撕计, ノイズを除去する。

5. 処理 4 のフィルタリングを施した通風,無風時画像よ り発光強度比 $I_{r e f} / I$ を求める。

6. 最終的な発光強度比の画像を得るために,訬度ローハ スフィルターを処理 5 の発光強度比の画像に掛ける。

7. デルタ翼上現象を視認しやすくするためグレ一画像 に適切な擬似力ラーを付与寸る。

処理 7 の部分で (1)式の厈ノと発光强度の関倸を与え れば,历ノ場の情報を求めることが出きる ${ }^{1,2)}$

処理 1 では,それぞれの条件で複数枚（今回は12 枚) の画像を平均化することにより,ノイズを除去している 平均枚数の $1 / 2$ 乗に比例して $\mathrm{S} / \mathrm{N}$ 比は良くなるとされて おり，叮能な限り多くの枚数を撮影寸ることが望ましい:

処理 3 の画像のずれの補止は,通風時にモデルの移動 や変形が起こり,無風時画像との間にずれが尘じ,人きな 䛊応要因となるのを防ぐために行った。Fig. 3 は無風时 と通風時のモデルの移動・変形を比較したものである: 通風時に人きくモデルが動いており,ずれの補止なしに は止しい测定が仙㑷であることを亦している。Fig. 4 にホすよよにプログラム上で無風時と通風時のデル夕翼 の 3 頂点の座標を水め,CAD 図面の形になるようにそれ ぞれの画像にアフィン変换を施すことにより 2 画像間 ずれを修止した。すなわち元図形の頂点座標を $\vec{x}$,変挨後 の座標を $\vec{a}$ とすると $\vec{x}=A \cdot \bar{a}$ ，つまり $A=\vec{x} \cdot \operatorname{in} v(\vec{a})$ と表 されるベクトルである。この補止によって,カメラアング ルによって企んだデルタ䝷の形が CAD 図面の形に戻り， 後のデータ解析が容易になる。

処理 4 仝び 6 のローパスフィルタ(ウィナー・フィルタ) は高空間周波数成分を市とするノイズを除去したり,画 像のサブピクセルの移動に起因する值の変動を平滑化寸 るために用いられた。 


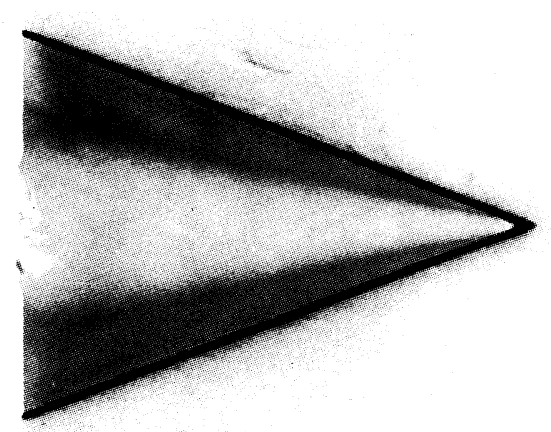

Fig. 3 Visualization without any process

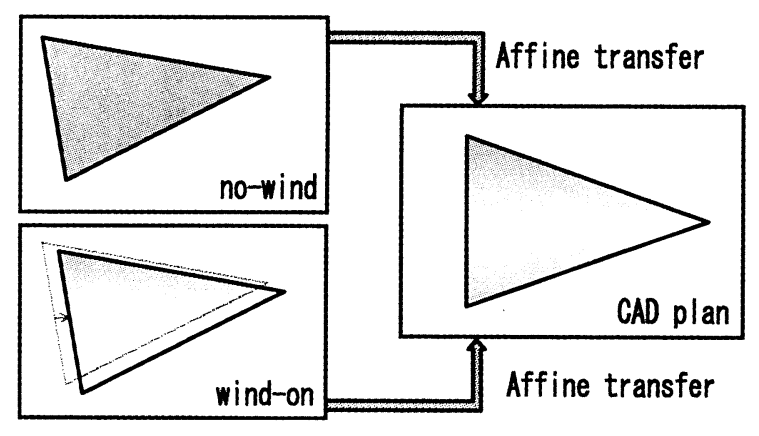

Fig. 4 Displacement correction by affine transfer
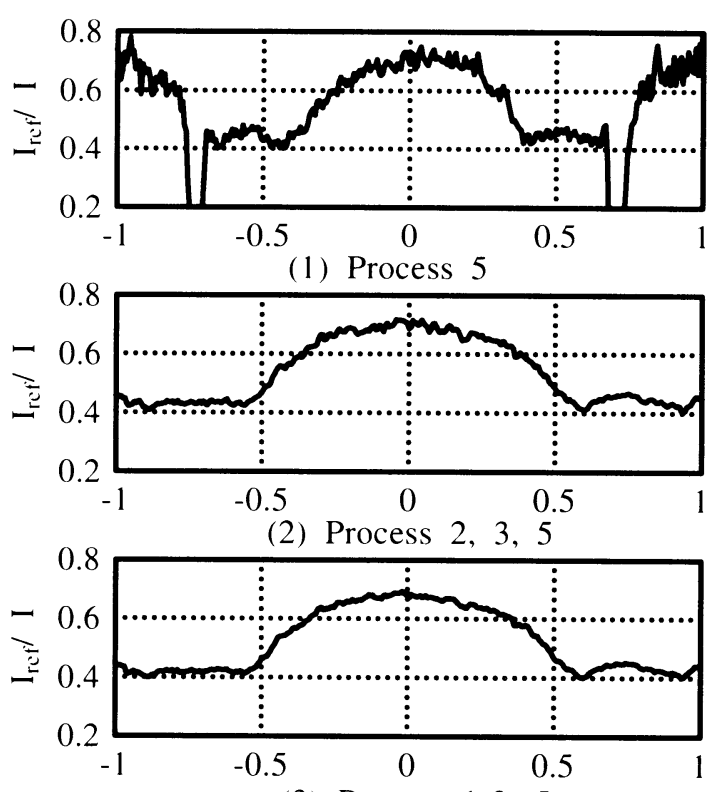

(3) Process 1-3, 5

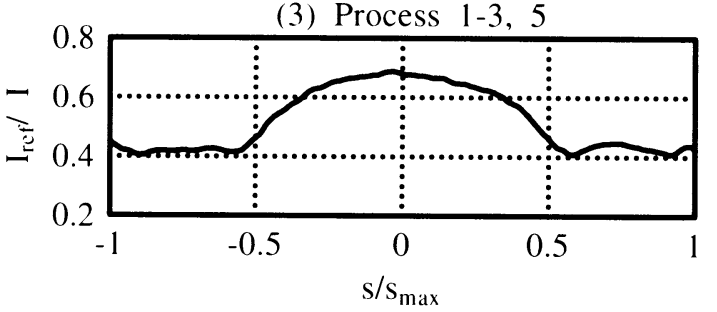

(4) Process 1-6

Fig. 5 Effect of image corrections at $M=0.78, \alpha=30^{\circ}, x / C=0.5$
それぞれの処理による效果を確認するために $M=0.78$, 迎角 $\alpha=20^{\circ}, \mathrm{x} / C=0.5$ の位.置における発光強度比 $I_{r e f} / I$ のスパン方向分有をFig. 5 に示す。(1)は木処理の場合で あり,Fig. 3 に胃られる通り，無風時と通風時の慔型のず れにより,ずれ補止を施した $(2) \sim(4)$ のものと比較して止 しい值を示していないことが判る。(2)は,処理 1 の平均 化処理を行わず, 1 枚だけの画像から得られた結果である。 (3) は処理 1 の 12 枚の平均化処理を行ったものであ り,(2)のものと比較してかなり平滑化されていることが わかる。(4)は処理 4 久び 6 のローパスフィル夕処理も行 ったものである。高空間周波数成分がかなり除去されて いる。しかし, 同時に微細現象の情報も失われてしまう危 険があるので, 現象の特徵を|・分考虑してフィルタリン グを行う必要がある。これら全部の処理を抗こなうこと により高空間周波数成分を市とするノイズを除去するこ とができた。これらの処理を施した無風時, 通風時 $\left(M=0.58, \alpha=20^{\circ}\right)$ 人びこれらの画像から得た発光強度 比 $I_{r e f} f$ の画像データをFig. 6 に示す。 $I_{r e f} I$ と $P_{r e f} / P$ は (1)式の Stern-Volmer の式で刘忍付けられる。感历塗料 のバインダーとしてフッ素系ポリパーを用いた場命,こ の関係は線形であり、Fig. 6 の $I_{\mathrm{ref}} d$ 分布はデル夕翼表面 上の厈分布を示していると考えてよい。

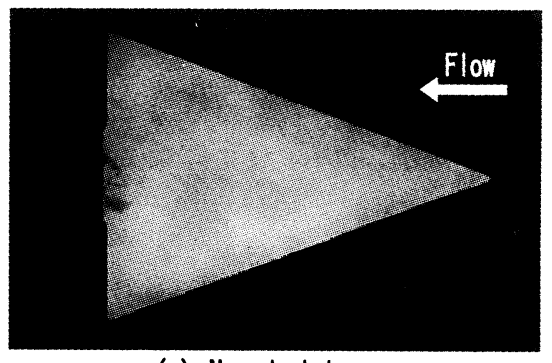

(a) No wind image

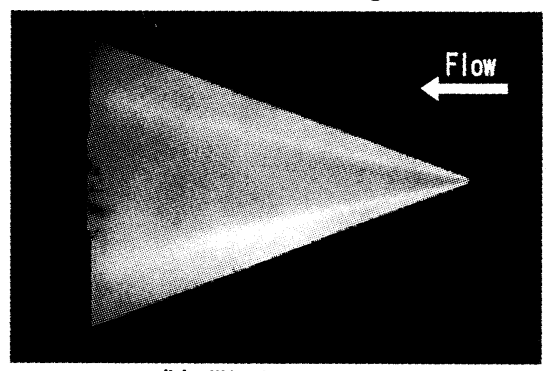

(b) Wind-on image

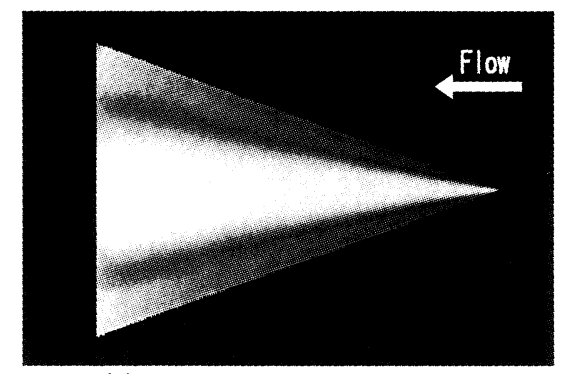

(c) Luminecence ratio /ref/I

Fig. 6 Image processing for visualization at $M=0.58, \alpha=20^{\circ}$ 


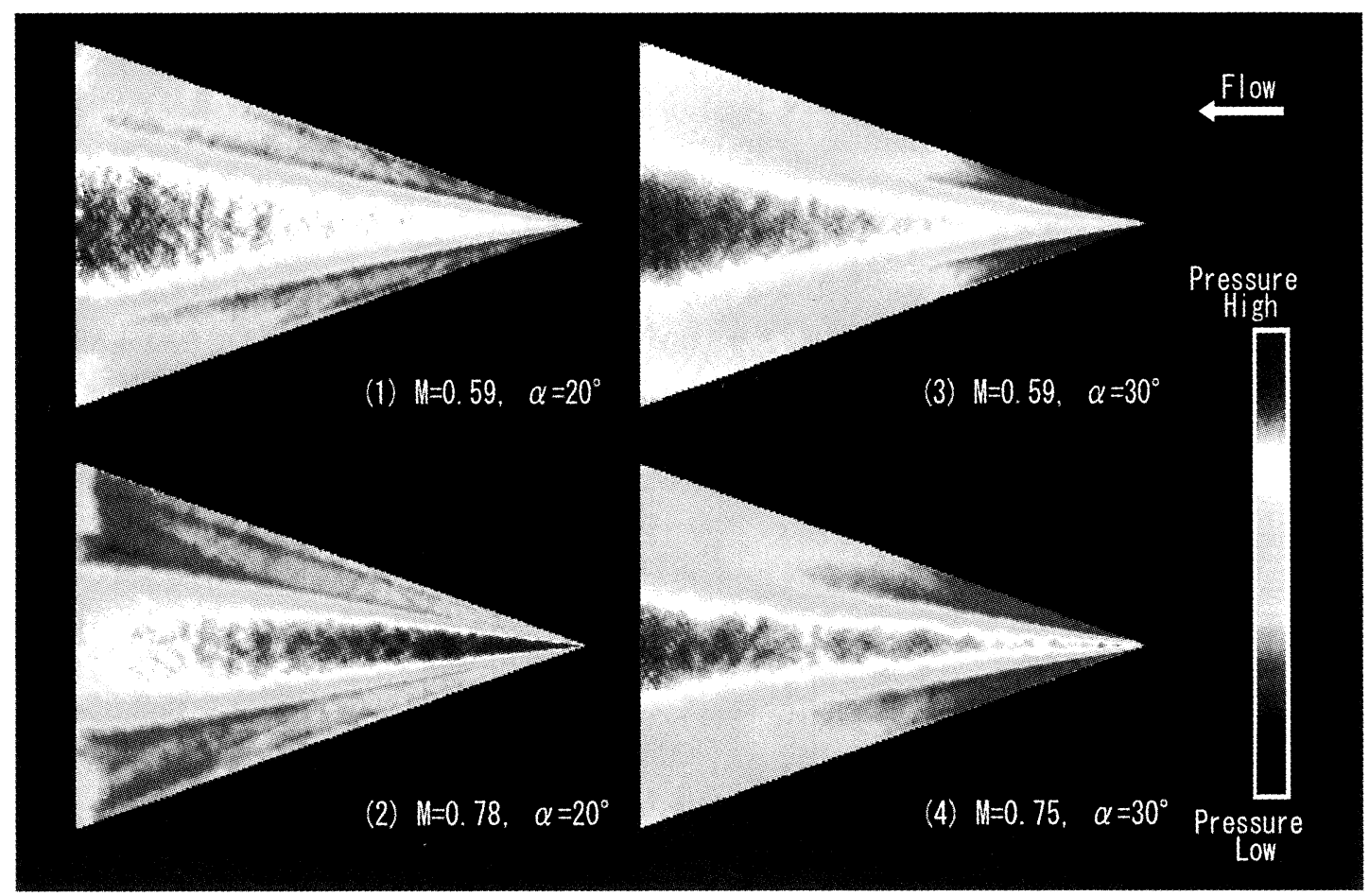

Fig. 7 Visualization of vortex breakdown on a delta wing

\section{4. 可視化結果}

以上の画像処理法により得られた結果をFig. 7 に示す。 これはFig. 6 に対して,より現象を容易に視覚的に捉え られるよう擬似カラーを与えたものである。

それぞれの図よりデルタ翼の前縁はく離渦が生じてい ることが明瞭にわかる。(1)の $M=0.59, \alpha=20^{\circ}$ では前 縁はく離渦が後縁付近までその構造を保ち,渦崩壊に至 つていることがわかる。またこの一次渦の外側,前縁に沿 って二次渦が形成されていることがわかる。さらに,デル 夕翼中央部の圧力の高い赤色の領域と,前縁はく離渦の 青色の領域に挟まった、緑色の領域の縁が渦の再付着線 に相当すると考えられる。また,前縁はく離渦の 1 次渦と 2 次渦の間の青色が少し薄くなった部分は 1 次渦と 2 次 渦の境界で,その縁は 2 次渦のはく離線に相当する。

(2)の $M=0.78, \alpha=20^{\circ}$ では(1)と比較してマッ八数が 増加した分,渦が強く形成されていることがわかる。前縁 はく離渦は後縁に達しても崩壊せず,保持されているこ とがわかる。また,圧力の高い領域が(1)では翼中央部, 後 縁に近い領域に分布していたものが,(2)では先端付近に 移動していることがわかる。また,他のケースでは低圧領 域は前縁に沿った翼先端に近い領域に広がっているが， このケースでは後縁に近い領域で最も圧力が低くなって いることも特徵的である。また, 1 次渦, 2 次渦とも強く形 成されており,渦形成領域では強い 1 次渦の回転に伴う, 外側向きの流れと似たようなパターンも見られた。

迎角を $\alpha=20^{\circ}$ から $30^{\circ}$ にすると前縁はく離渦の崩壊
位置は上流側に移動した。(3)の $M=0.59, \alpha=30^{\circ}$ ではx/C $=0.45$ 付近で渦崩壊が生じている。揚力を発生寸る低圧 領域はデルタ翼先端付近の前縁に沿った領域に限られて いる。また後縁付近の高圧領域も大きく広がっているこ とがわかる。(4)の $M=0.78, \alpha=30^{\circ}$ ではマッ八数の増加 に伴い, 渦崩壊位置は $70 \%$ 程まで回復した。

また、 $M=0.6, \alpha=30^{\circ}$ において総圧 $P$ を $60 \sim 100 \mathrm{kPa}$ に変化させることによりレイノルズ数 $R e$ を $6.1 \times 10^{5} \sim$ $10.1 \times 10^{5}$ 変化させた試験を行った。その場合は、渦 崩壊位置や渦構造に大きな変化は見られなかった。

このように適切な画像解析を施すことにより感圧塗料 を用いた流れ場の詳細な可視化を行うことができた。

\section{5. 結 言}

感圧塗料を用いた,デルタ翼表面の流れ場の可視化を 試みた。画像処理を行うことによりノイズやずれなよ゙の 誤差要因を低減することができた。それによりデル夕翼 表面の圧力場を詳細に観察することができ,前縁はく離 渦の 1 次渦, 2 次渦の形成や渦崩壊位置の変化などの現象 を明瞭に捉えることができた。

これらの手法を使うことにより容易に物体表面の圧力 場の情報を得ることができることを明らかにした。

\section{参考文献}

1) 藤敦彦,他: フッ素系ボリマーを用いた感圧塗料の特性評 価，第 28 回可視化情報シンボジウム, (2000).

2) 浅井圭介: 感圧塗料による圧力分布の計測技術, 可視化情 報 Vol.18 No.69 (1998) pp.97-103. 